\title{
Long-Term Effect of Alendronate on Bone Mineral Density in Postmenopausal Type 2 Diabetes Mellitus
}

\author{
Tadasu Ikeda* and Keiko Iwata
}

Department of Adult and Geriatric Nursing, School of Health Sciences, Faculty of Medicine, Tottori University, Japan

\begin{abstract}
The purpose of this study was to investigate the long-term effect of anti-resorptive agent, alendronate, on bone mineral density (BMD) in postmenopausal osteoporotic diabetic women. Twelve postmenopausal type 2 diabetic women (mean age; $70.4 \pm 5.4 \mathrm{yrs}$, duration of diabetes; $13.1 \pm 3.9 \mathrm{yrs}$ ) were administered alendronate sodium (5 $\mathrm{mg} /$ day) for 5 years. The radial BMD and urinary N-telopeptide cross-linked collagen type (NTx), one of biochemical markers, were measured every year. These parameters were compared with those in age-matched 12 control postmenopausal diabetic women not treated with alendronate. The radial BMD significantly $(p<0.05)$ decreased by $5.30 \%$ at $2 \mathrm{yr}, 8.38 \%$ at $3 \mathrm{yr}, 9.71 \%$ at $4 \mathrm{yr}$, and $11.12 \%$ at $5 \mathrm{yr}$, in control subjects. While, radial BMD did not significantly change in diabetic women treated with alendronate. The decrease in radial BMD was significantly greater in control subjects than in subjects treated with alendronate at 3, 4, and 5year. Urinary NTx significantly decreased only in women with alendronate treatment. These data suggest that long-term administration of alendronate inhibits the decrease in BMD in postmenopausal type 2 diabetic women with low BMD.
\end{abstract}

Keywords: Alendronate; Bone mineral density; Type 2 diabetes mellitus; Urinary NTx

\section{Introduction}

It has been reported that type 2 diabetes is a risk factor for hip, proximal humerus, and foot fractures among older women [1,2]. It is also demonstrated that postmenopausal women who have diabetes had a 1.40 1.70-fold higher risk of incident hip fracture than women without diabetes [3-5]. These studies suggest that fracture prevention efforts should be an important consideration in the treatment of diabetes in older women.

Several studies have indicated that the anti-resorptive agent alendronate, a potent aminobisphosphonate, has been shown to increase bone mineral density (BMD) at the hip and spine and decrease the incidence of osteoporotic fractures in older women [6-8]. In a previous study, we suggested that one year of alendronate treatment have a clinical significance in postmenopausal type 2 diabetic women with low BMD [9]. Similarly, Keegan et al. [10] reported that three years of alendronate treatment was associated with increased BMD at all studied, including $6.6 \%$ at the lumbar spine and $2.4 \%$ at the hip in older women with type 2 diabetes. While, Dagdelen et al. [11] reported that postmenopausal type 2 diabetes are resistant to long-term (4.8year) bisphosphonate treatment. The present study was examined to elucidate the long-term effect of alendronate on radial BMD, $\mathrm{HbAlc}$, and changes in biochemical marker of resorption, urinary NTx, in postmenopausal women with type 2 diabetes.

\section{Materials and Methods}

\section{Subjects}

Twenty-four postmenopausal women who have type 2 diabetes mellitus (aged 59-80 year) were enrolled in the present study from April to September 2005. Inclusion criteria were 1) postmenopausal women of at least 10 year's duration of diabetes, 2) urinary N-telopeptide cross-linked collagen type (NTx) was more than $40 \mathrm{nmol}$ bone collagen equivalents $(\mathrm{BCE}) / \mathrm{mmol}$ creatinine $(\mathrm{Cr})$, and 3) radial $\mathrm{BMD}$ was less than $0.400 \mathrm{~g} / \mathrm{cm}^{2}$. Potential subjects were excluded if they had a history of any illness affecting bone metabolism [e.g., renal failure, microalbuminuria ( $\geqq 30 \mathrm{mg} / \mathrm{g}$.cr), hepatic failure, active malignancy, hyperthyroidism, hyperparathyroidism, or malabsorption], or had been treated for osteoporosis with hormone replacement therapy or calcitonin. Subjects treating with diuretics were also excluded. Their diabetic condition was stable and informed consent was obtained from the subjects. Thus, 12 subjects (mean age; $70.4 \pm 5.4$ yrs, duration of diabetes; $13.1 \pm 3.9 \mathrm{yrs}$ ) were administered alendronate sodium (Banyu Pharma. Co., Osaka) per os in a dose of $5 \mathrm{mg}$ (once daily) or $35 \mathrm{mg}$ (once weekly), 30minutes before breakfast. Twelve subjects (mean age; $70.1 \pm$ $6.4 \mathrm{yrs}$, duration of diabetes; $12.8 \pm 2.4 \mathrm{yrs}$ ) refused to take medicine (alendronate) because of no clinical symptoms etc. They were served as a control. The therapeutic trial lasted 5 years. During the study, subjects continued their standard antidiabetic therapy, diet, oral hypoglycemic agents, or insulin. The dosage was appropriately changed to obtain better glycemic control in all the subject. The clinical characteristics of the subject are shown in Table 1.

\section{Biochemical markers}

Following an overnight fast, we obtained a second-void 2-h urine collection. All samples were frozen at $-20^{\circ} \mathrm{C}$. Urinary $\mathrm{N}$-telopeptide cross-linked collagen type I [NTx, nmol bone collagen equivalents(BCE)/mmol creatinine(Cr)] was measured with an enzyme-linked immunosorbent assay [12]. Urinary NTx was measured at baseline and every year.

\section{Bone mineral density}

Bone mineral density (BMD, $\mathrm{g} / \mathrm{cm}^{2}$ ) of radius (ultradistal) were

${ }^{*}$ Corresponding author: Tadasu Ikeda, MD, Department of Adult and Geriatric Nursing, School of Health Sciences, Faculty of Medicine, Tottori University, Nishicho 86, Yonago 683-8503, Japan, Tel:0859-38-6316; Fax:0859-38-6316; E-mail: ikeda@grape.med.tottori-u.ac.jp

Received September 14, 2011; Accepted October 10, 2011; Published November 20, 2011

Citation: Ikeda T, Iwata K (2011) Long-Term Effect of Alendronate on Bone Minera Density in Postmenopausal Type 2 Diabetes Mellitus. J Diabetes Metab S1:002. doi:10.4172/2155-6156.S1-002

Copyright: (c) 2011 Ikeda T, et al. This is an open-access article distributed unde the terms of the Creative Commons Attribution License, which permits unrestricted use, distribution, and reproduction in any medium, provided the original author and source are credited. 


\begin{tabular}{|c|c|c|}
\hline & Alendronate $(n=12)$ & Control $(n=12)$ \\
\hline Age (yr) & $70.4 \pm 5.4$ & $70.1 \pm 6.4$ \\
\hline BMI $\left(\mathrm{kg} / \mathrm{m}^{2}\right)$ & $23.8 \pm 4.2$ & $24.1 \pm 3.5$ \\
\hline \multicolumn{3}{|l|}{ Treatment of diabetes } \\
\hline Diet & 1 & 1 \\
\hline $\mathrm{OHA}$ & 5 & 6 \\
\hline Insulin & 6 & 5 \\
\hline $\mathrm{HbA1c}(\%)$ & $76 \pm 14$ & $73 \pm 15$ \\
\hline Duration & $13.1 \pm 3.9$ & $12.8 \pm 2.4$ \\
\hline Urinary NTx (nmol BCE/mmol Cr) & $68.7 \pm 12.5$ & $60.3 \pm 13.2$ \\
\hline $\mathrm{BMD}\left(\mathrm{g} / \mathrm{cm}^{2}\right)$ & $0.296 \pm 0.066$ & $0.318 \pm 0.041$ \\
\hline
\end{tabular}

OHA: oral hypoglycemic agent, BMD: bone mineral density

Table 1: Characteristics of the subject.

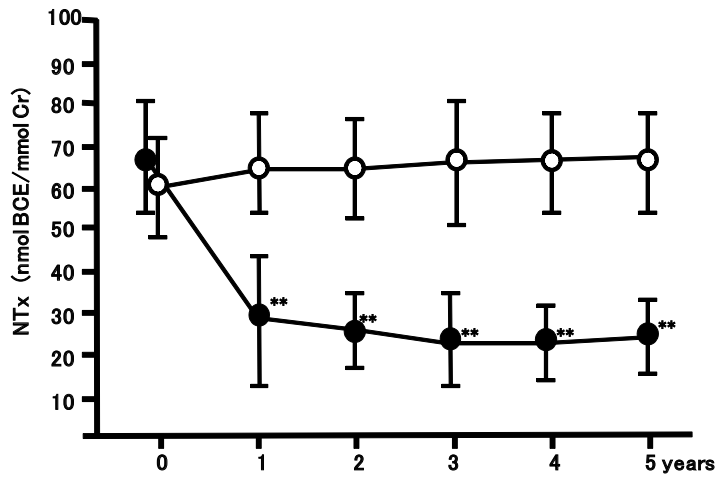

control group $(n=12)$

-alendronate group $(n=12)$

${ }^{* *} p<0.0001$, significantly different from baseline

Figure 1: Changes in urinary NTx.

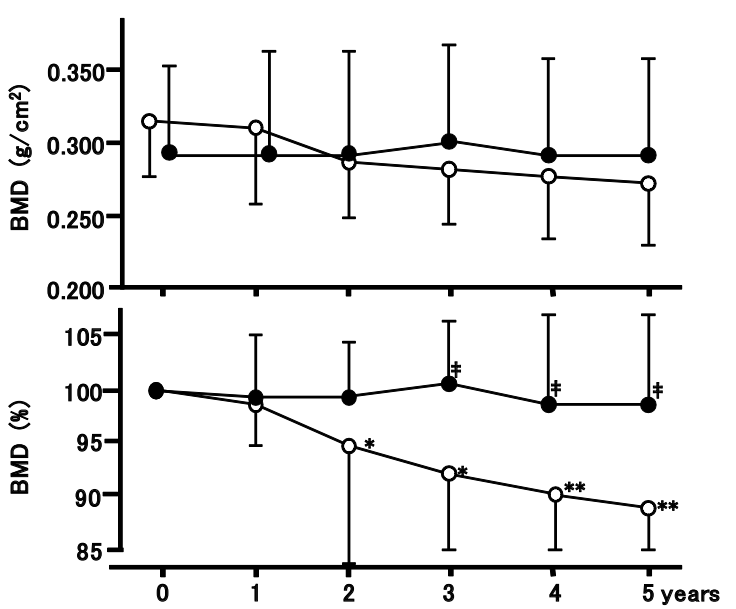

control group $(n=12)$

- alendronate group $(n=12)$

${ }^{*} p<0.05,{ }^{* *} p<0.001$, significantly different from baseline

$\pm p<0.05$, significantly different from control

Figure 2: Changes in radial bone mineral density.

measured by dual-energy X-ray absorptiometry at baseline and every year.

\section{Statistical analysis}

The data were expressed as the means \pm SD. Statistical difference between groups was determined by ANOVA and two-tailed Student's paired $t$-test. Wilcoxon test were used to evaluate the intra-subject variability of the NTx and radial BMD. Correlation was tested using Pearson's method. A p value $<0.05$ was considered statisitically significant.

\section{Results}

\section{Characteristics of the subject}

Characteristics of the subject were shown in (Table 1). The age, BMI, duration of diabetes, mode of therapy, HbAlc level, urinary NTx, and radial BMD were not significantly different between two groups. Alendronate were well tolerated in all subjects. Abnormal laboratory findings of renal or hepatic function did not occur by alendronate administration.

\section{Glycemic control}

The basal $\mathrm{HbA} 1 \mathrm{c}$ value was $7.6 \pm 1.4 \%$ and $7.3 \pm 1.5 \%$ in alendronate and control group. HbA1c level fell progressively from baseline to $7.3 \pm$ $1.4 \%$ and to $7.0 \pm 1.2 \%$ in two groups after 5 years, respectively. There were no significant differences $(\mathrm{p}<0.60)$ between two groups.

\section{Changes in urinary NTx}

As shown in (Figure 1), baseline levels of urinary NTx were 68.7 $\pm 12.5 \mathrm{nmol} \mathrm{BCE} / \mathrm{mmol} \mathrm{Cr}$ and $60.3 \pm 13.2 \mathrm{nmol} \mathrm{BCE} / \mathrm{mmol} \mathrm{Cr}$ in subjects treated with alendronate and controls, respectively. There were no significant differences between two groups. After 1 year, urinary NTx was significantly $(\mathrm{p}<0.0001)$ decreased to the level of $31.3 \pm 12.6$ $\mathrm{nmol} \mathrm{BCE} / \mathrm{mmol} \mathrm{Cr}$ in subjects treated with alendronate, and these values were maintained for 5 years. In control subjects, urinary NTx did not significantly $(\mathrm{p}<0.2)$ change from $60.3 \pm 13.2 \mathrm{nmol} \mathrm{BCE} / \mathrm{mmol}$ $\mathrm{Cr}$ to $67.4 \pm 12.8 \mathrm{nmol} \mathrm{BCE} / \mathrm{mmol} \mathrm{Cr}$ for 5 years.

\section{Changes in radial BMD}

As shown in (Figure 2), baseline levels of radial BMD were $0.296 \pm$ $0.066 \mathrm{~g} / \mathrm{cm}^{2}$ and $0.318 \pm 0.041 \mathrm{~g} / \mathrm{cm}^{2}$ in subjects treated with alendronate and controls, respectively. There were no significant differences between two groups. After 5 years, the radial BMD was $0.294 \pm 0.058 \mathrm{~g} /$ $\mathrm{cm}^{2}$ and $0.279 \pm 0.044 \mathrm{~g} / \mathrm{cm}^{2}$ in subjects treated with alendronate and controls, respectively. The mean percent change in radial BMD fell gradually and significantly $(\mathrm{p}<0.05)$ from baseline to the level of 88.88 $\pm 5.90 \%$ at 5 year in control subjects. While, the mean percent change in radial BMD at 5 year slightly, but not significantly, decreased to the level of $99.30 \pm 8.36 \%$ in subjects treated with alendronate. The percent decrease in radial BMD was significantly greater in control subjects compared to subjects treated with alendronate at 3,4 , and 5 year.

\section{Correlation between decrease in urinary NTx and change in radial BMD}

There was no significant correlation between the decrease in urinary NTx and change in radial BMD $(r=0.098, p=0.762)$.

\section{Discussion}

Several investigators have reported higher bone mass in type 2 diabetic patients $[13,14]$. While, other investigators have reported that individuals with type 2 diabetes had lower bone density relative to nondiabetic control subjects [15-17]. Thus contradictory results were obtained in the bone density in type 2 diabetes. In recent prospective studies, type 2 diabetes is a risk factor for bone fractures in older women, and that postmenopausal diabetic women had a 1.40 1.70-fold 
higher risk of incident hip fracture than women without diabetes [1,35]. These suggest that fracture prevention efforts should be necessary in the treatment of diabetic women, especially in postmenopausal women.

Radial BMD gradually and significantly decreased in control subjects at 2, 3, 4 and 5 year in the present study. This result agreed with the report of Keegan et al that BMD decreased in diabetic women treated with placebo for 3 years [10]. Dagdelen et al. [11] have indicated that postmenopausal type 2 diabetes are resistant to longterm bisphosphonate treatment. Keegan et al. [10], however, reported that three years of alendronate treatment was associated with increased BMD (6.6\% at the lumbar spine and $2.4 \%$ at the hip) in women with type 2 diabetes. In the present study, alendronate treatment significantly decreased urinary NTx, one of biochemical markers of bone resorption, and inhibited the decrease in radial BMD for 5 years. The present result confirmed that alendronate is available for improving bone turnover in postmenopausal women with type 2 diabetes. The differences of these results may be due to the difference of species and/or experimental methods. Although Schwartz et al. [18] have reported that long-term use of thiazolidinediones caused reduction of whole body bone mineral density in older type 2 diabetic women, there were no subjects treated with thiazolidinediones in the presen study.

Several studies have reported that urinary NTx is a more specific marker of bone resorption in patients treated with bisphosphonates compared with other markers [19,20]. There have been a report that changes in urinary NTx following therapy were predictive of improvements of bone mineral density in elderly women, and that the percent decrease in urinary NTx had the greatest association with long-term increases in BMD [21]. Garnero and colleagues found an association between changes in biochemical markers at 6 month and increased spinal BMD after 2 years in postmenopausal women treated with bisphosphonates [22]. It has been reported that subjects with the greatest drop in urinary cross-linked collagen (65\% or more) demonstrated the greatest gains in radial bone density [21]. In the present study, significant correlation was not observed between the decrease in urinary NTx and change in radial BMD. This difference may be due to the small number of our present study.

In the present study, alendronate treatment significantly decreased urinary NTx by $60 \%$ in postmenopausal diabetic women, and inhibited the decrease in mean radial BMD for 5 years, although the mean radial BMD progressively and significantly decreased by $11 \%$ in control subjects. It has been reported that a $70 \%$ reduction in resorption biochemical markers of bone turnover would reduce fracture risk by $40 \%$ [23], and that in a meta-analysis of placebo-controlled trials, $1 \%$ increase in spine BMD at 1 year was association with an $8 \%$ reduction in nonvertebral fracture risk in postmenopausal women [8]. These and the present results suggest that alendronate administration would be expected at least to inhibit the decrease in BMD and to reduce the risk of bone fracture in postmenopausal osteoporotic type 2 diabetic women. The present study was not large enough to examine fracture outcomes. Viegas et al. [24] have reported that the prevalence of vertebral fractures has higher in postmenopausal type 2 diabetic women with lower bone mineral density. However, Yamaguchi et al. [25] have suggested that type 2 diabetes patients have an increased risk of vertebral fractures independent of bone mineral density. Further studies should be necessary to know if this result is associated with improvement of BMD in other bone sites and is able to reduce fractures.

Finally, the subjects had stable glycosylated hemoglobin levels throughout the study, although the diabetic treatment was appropriately changed. These suggest that alendronate treatment did modify neither the modalities of the anti-diabetic treatment nor the glycemic pattern.

\section{References}

1. Schwartz AV, Sellmeyer DE, Ensrud KE, Cauley JA, Tabor HK, et al. (2001) Older women with diabetes have an increased risk of fracture: a prospective study. J Clin Endocrinol Metab 86: 32-38.

2. Melton LJ, Leibson CL, Achenbach SJ, Therneau TM, Khosla S (2008) Fracture risk in type 2 diabetes: Update of a population-based study. J Bone Miner Res 23: $1334-1342$

3. Nicodemus KK, Folsom AR (2001) Type 1 and type 2 diabetes and incident hip fracture in postmenopausal women. Diabetes Care 24: 1192-1197.

4. Vestergaard $P$ (2007) Discrepancies in bone mineral density and fracture risk in patients with type 1 and 2 diabetes-a meta-analysis. Osteoporos Int 18: 427 444

5. Janghorbani M, Dam RM, Willett WC, Hu FB (2007) Systemic review of type 1 and 2 diabetes mellitus and risk of fracture. Am J Epidemiol 166: 495-505.

6. Liberman UA, Weiss SR, Broll J, Minne HW, Quan H, et al. (1995) Effect of oral alendronate on bone mineral density and the incidence of fractures in postmenopausal osteoporosis. N Engl J Med 333: 1437-1443.

7. Black DM, Cummings SR, Karpf DB, Cauley JA, Thompson DE, et al. (1996) Randomised trial of effect of alendronate on risk of fracture in women with existing vertebral fractures. Lancet 348: 1535-1541.

8. Karpf DB, Shapiro DR, Seeman E, Ensrud KE, Johnston CC, et al. (1997) Prevention of nonvertebral fractures by alendronate: A meta-analysis. JAMA 277: $1159-1164$

9. Ikeda T, Manabe H, Iwata K. (2004) Clinical significance of alendronate in postmenopausal type 2 diabetes mellitus. Diabetes Metab 30: 355-358.

10. Keegan THM, Sellmeyer DE, Schwartz AV, Kelsey JL, Bauer DC (2004) Effect of alendronate on bone mineral density and biochemical markers of bone turnover in type 2 diabetic women. The fracture intervention trial. Diabetes Care 27: 1547-1553

11. Dagdelen S, Sener D, Bayraktar M (2007) Influence of type 2 diabetes mellitus on bone mineral density response to bisphosphonates in late postmenopausal osteoporosis. Adv Ther 24: 1314-1320.

12. Hanson DA, Weis ME, Bollen A-M, Maslan SL, Singer FR, et al. (1992) A specific immunoassay for monitoring human bone resorption: Quantitation of type I collagen cross-linked N-telopeptides in urine. J Bone Miner Res 7: 1251 1258

13. Johnston CC, Hui SL, Longcope C (1985) Bone mass and sex steroid concentrations in postmenopausal Caucasian diabetics. Metabolism 34: 544 550 .

14. van Daele PL, Stolk RP, Burger H, Algra D, Grobbee DE, et al. (1995) Bone density in non-insulin-dependent diabetes mellitus: the Rotterdam study. Ann Intern Med 122: 409-414.

15. Isaia G, Bodrato L, Carlevatto V, Mussetta M, Salomono G, et al. (1987) Osteoporosis in type II diabetes. Acta Diabetol Lat 24: 305-310.

16. Haffner SM, Bauer RL (1993) The association of obesity and glucose and insulin concentrations with bone density in premenopausal and postmenopausal women. Metabolism 6: 735-738

17. Zhou Y, Li Y, Zhang D, Wang J, Yang H (2010) Prevalence and predictors of osteopenia and osteoporosis in postmenopausal Chinese women with type 2 diabetes. Diabetes Res Clin Prac 26: 1-9.

18. Schwartz AV, Sellmeyer DE, Vittinghoff E, Palermo L, Lecka-Czernik B, et al. (2006) Thiazolidindione use and bone loss in older diabetic adults. J Clin Endocrinol Metab 91: 3349-3355

19. Rosen HN, Dresner-Pollak R, Moses AC, Rosenblatt M, Zeind AJ, et al. (1994) Specificity of urinary excretion of cross-linked N-telopeptides of type I collagen as a marker of bone turnover. Calcif Tissue Int 54: 26-29.

20. Garnero P, Gineyts E, Arbault P, Christiansen C, Delmas PD (1995) Different effects of bisphosphonate and estrogen therapy on free and peptide-bound bone cross-links excretion. J Bone Miner Res 10: 641-649.

21. Greenspan SL, Parker RA, Ferguson L, Rosen HN, Maitland-Ramsay L, et al. (1998) Early changes in biochemical markers of bone turnover predict the long-term response to alendronate therapy in representative elderly women: A randomised clinical trial. J Bone Mineral Res 13: 1431-1438. 
Citation: Ikeda T, Iwata K (2011) Long-Term Effect of Alendronate on Bone Mineral Density in Postmenopausal Type 2 Diabetes Mellitus. J Diabetes Metab S1:002. doi:10.4172/2155-6156.S1-002

Page 4 of 4

22. Garnero P, Shih WJ, Gineyts E, Karpf DB, Delmas PD (1994) Comparison of new biochemical markers of bone turnover in late postmenopausal osteoporotic women in response to alendronate treatment. J Clin Endocrinol Metab 79: 1693-1700.

23. Hochberg MC, Greenspan S, Wasnich RD, Miller P, Thompson DE, et al. (2002) Changes in bone density and turnover explain the reduction in incidence of nonvertebral fractures that occur during treatment with antiresorptive agents. J Clin Endocrinol Metab 87: 1586-1592.
24. Viegas M, Costa C, Lopes A Griz L, Medeiro MA et al. (2011) Prevalence of osteoporosis and vertebral fractures in postmenopausal women with type 2 diabetes mellitus and their relationship with duration of the disease and chronic complications. J Diabetes Complications. 25: 216-221.

25. Yamaguchi T, Sugimoto T (2011) Bone metabolism and fracture risk in type 2 diabetes mellitus. Endcr J 58: 613-624.

This article was originally published in a special issue, Diabetic Osteoporosis handled by Editor(s). Dr. Laura McCabe, Michigan State University, USA 